\title{
Cognitive rehabilitation system for children with autism spectrum disorder using serious games: A pilot study
}

\author{
Nuria Aresti-Bartolome* and Begonya Garcia-Zapirain \\ DeustoTech-LIFE Unit University of Deusto, Universities Avenue 24, 48007 Bilbao, +34944139000, \\ Spain
}

\begin{abstract}
This paper studies and assesses how rehabilitation activities and supervised computer games incorporated into a system aimed at people diagnosed with Autism Spectrum Disorder (ASD) can be used to work on the areas affected by ASD at any time and in any place. This research specifically assesses the areas that affect communication and interaction between people with ASD and professionals. In order to do this, a group of 20 children diagnosed with ASD of between 3 and 8 years old (clinical group) was used, together with a group of 20 children of between 3 and 8 years old with a neurotypical development, which served as a control group. During the tests, response time and visual interaction with the session leader were evaluated. Despite the fact that the clinical group spent more time $(M=21.08 \mathrm{sec})$ than the control group (M=4.52) to interact leader, eye contact predominated in the interaction. As a result of the pilot study, the system obtained could help in cognitive rehabilitation.
\end{abstract}

Keywords: Eyetracking, rehabilitation, ASD, interaction

\section{Introduction}

Some studies have been published which show that in recent years there has been an increase in Autism Spectrum Disorder (ASD) cases by 78\% since $2002[1,2]$.This fact has been attributed by various authors to better awareness [3], easier recognition and better diagnosis of the disorder, the inclusion of cases of lower severity within the spectrum [4] and the comorbidity with other disorders such as Attention Deficit Hyperactivity Disorder [5], as well as to continuing changes in the definition of ASD [6] made in the Diagnostic and Statistical Manual of Mental Disorders. However, it must be noted that there is a lack of consensus regarding the prevalence of ASD. Recent studies published in March 2014 by the Center for Disease Control and Prevention (CDC) show that about 1 in 68 children has been identified with autism spectrum disorder (ASD) in the USA [7]. There are publications that show that 1 child out of every 150 or 110 out of every 10,000 children were affected in 2009 [8], and studies conducted on pre-school age children in Spain that show a prevalence of $8.1 \%$ and $11.7 \%$. The study presented by Mayada, et al. [9] confirms an average estimated prevalence of 62 per 10,000.

\footnotetext{
${ }^{*}$ Address for correspondence: Nuria Aresti-Bartolome, DeustoTech-LIFE Unit University of Deusto, Avda. Universidades 24, 48007 Bilbao, +34944139000, Spain. Tel.: +43-943-32-6600 (ext. 2051); E-mail: mbgarciazapi@deusto.es.
}

0959-2989/15/\$35.00 @ 2015 - IOS Press and the authors. 
Given the increase in diagnosed ASD cases in recent decades, some hardware such as eye tracker [10] and software solutions have started to be developed which are aimed at people with autism. These applications may be grouped into three broad categories:

(1) Mixed reality games: games incorporate virtual elements into a real world. Positive results have been obtained using this technology in certain fields, and they can be used for cognitive rehabilitation purposes by offering secure repetitive environments [11].Virtual reality makes it possible to create safe environments [12] where they can learn rules and repeat the tasks [13]. Furthermore, interacting with avatars where social situations are replicated enables patients to work on these situations and find more flexible solutions $[14,15]$. This means that virtual environments may prove to be good instruments to work on social skills with ASD sufferers [16-18].

(2) Robots: robotized toys practiced and worked both on social skills and new skills. Besides, the collaborative games may be learned through these robots [19], and these types of system may help to improve fine motor skills such as those in which the use of the wrist is involved [20]. Robot toys can help special needs children to work on social skills, learn new skills and discover the different game modes-in other words, show them that collaborative games also exist [21]. Thus, social robots may become very useful tools in therapy with ASD children [22] $[23,24]$ Due to the inclusion of social robots in therapy, it has even observed how the children's limited interests and repetitive behavior have improved [25]. However, although robots are an effective tool, we should not forget that collaboration from people is always needed in therapy or treatment $[21,26]$. Not all robots achieve the same objective, and so it is interesting for therapy robots to be equipped with voice technology in order to foster social skills in people with autism [27].

(3) Dedicated Applications: technological tools designed to work in computers, tablets or mobiles, such as communicators [28]. Applications of this type have been used to work on areas affected by autism $[29,30]$ and conditions related to Autism Spectrum Disorder, mainly concentrating on creating applications that help people with autism to communicate through images and sounds [31-33]. These systems are widely accepted because they are simple to use and contain very intuitive tools, since they work with everyday items [34].

With new technologies, one is able to get a closer look at the lonely world of autism, prompting a better understanding of ASD sufferers' mental state and helping them to develop skills $[35,36]$ which would not be possible without subject-technology interaction. ICTs work to penetrate the isolation of people with autism and bring them out of the "world apart" in which they live [37]. The use of these technologies has been so successful that research using ICTs has increased from one publication in 1970 to more than 38 a year at the present time [38], appearing not only in impact journals targeting the social field [39], but also in the technical field [40, 41]. In addition to scientific research, there are a large number of blogs where family members post how their children interact with them. Specialist literature contains numerous reviews of studies including technology as support and help tools, proving the benefits of their use. Examples include the work by Ploog, et al. [37], Wang, et al. [42] or Scassellati, et al. [43].

Therefore, these types of solutions enable people with ASD to practice their strengths and work on their weaknesses, [44] helping them to increase their vocabulary and their communication, so that they can improve these skills [32, 45-48]. However, these studies present an important limitation: most of the researches involve people with autism working individually with the tool (interaction with virtual avatars) losing the interaction with other people.

The main purpose of the pilot study is to assess the interaction between children with ASD and the 
therapists objectively, using games and eyetracking technology.

Three aims have been identified to achieve this main objective. They are:

(1) To develop a game system which allows the rehabilitation of the affected areas of ASD (O1).

(2) To assess the interaction with people with ASD in the course of the activities incorporated into the system through objective variables $(\mathrm{O} 2)$.

(3) To establish objective indicators which allow cognitive behavior between people with ASD and people with a neurotypical development to be compared (O3).

The paper is organized as follows: first of all, the Methods section gives details of the participants and the experiment. The findings of the study are presented in the Results section, followed by a discussion and an outline of the various conclusions drawn.

\section{Methods}

The members who have participated in the experiment, materials, data analysis are shown in this section.

\subsection{Statistical methods}

Data was analyzed using SPSS (version 20) with a 5\% significance level $(\mathrm{p}=0.05)$. The MannWhithney-parametric test was used to establish significance between the clinical group and the control group. In so doing, one was able to determine whether the system could be used as a cognitive rehabilitation tool. Therefore, the Spearman statistic test was used to analyze the correlation between: 1) response time looking into the eyes of the session leader and 2) the number of times that this interaction was performed.

\subsection{Informed consent-institutional review board (IRB)}

Research ethics committee standards were met when conducting this research study. The parents of the participants were informed of the study's objective, the rights of the participants and the possible risks inherent in the tests. An informed consent form was required to be signed by family members in order for the children to participate in the study. It is important to stress that the risks attached to the system are minimal as it is a non-invasive system and it employs activities that the participants use on a regular basis.

\subsection{Materials}

A 21" touch screen was used for the tests in order to engage the attention of the children and to increase their motivation. Furthermore, a tactile pointer of $40 \mathrm{~cm}$ in length was manufactured in order to deal with the problem detected when using the mouse, as most of the participants had neither the knowledge nor sufficient skills required to handle it. Besides, participant eye gaze behavior was recorded using a Tobii X1Ligth eye tracker with infra-red cameras. Gaze and pupil information was sampled at a frequency of $32 \mathrm{~Hz}$.

\subsection{Participants}


20 children between 3 and 8 years old comprised the clinical group and participated in the supervised activities. These children had already been diagnosed only with ASD and covered the whole spectrum of autism, in accordance with the Diagnostic and Statistical Manual of Mental Disorders criteria, and they regularly attended treatment sessions with the professionals involved in the study. As well as the clinical group, 20 children with a neurotypical development, aged between 3 and 8 years old, formed the control group. These children had no physical or mental impairment. The two groups were paired according to gender and age. Neither the gender of participants nor socioeconomic aspects were taken into account. A multidisciplinary group made up of psychologists, educationalists and engineers participated throughout the whole process of the study (specification, design, development and tests).

\section{Experimental section}

With a view to meeting the objectives set out in this preliminary study, three major aspects were established so as to conduct the experiment properly: configuration of the games, selection of the environment in which the experiment is to be conducted and the optimum configuration of the eyetracker.

\subsection{Configuration of the games}

Professionals from the APNABI Association were asked to configure the game. Individuals with children with ASD also took part in different sessions, in the course of which the different exercises they carried out in order to work on the children's strong and weak points were analyzed. Both the levels of difficulty and the mode of play were defined and established as a result of these sessions and the meetings with professionals. This system deals with the cognitive rehabilitation of people affected by ASD, in particular the interaction between the child and the session leader. Furthermore, to be able to assess the users' evolution, a number of parameters and some variables related to the game were established in order to objectively define how the children show an interest in those guiding them during the game (see Table 1).

Table 1

Variables to be stored. The table shows the variables that are stored during the game, together with the goals and the objectives to which they refer

\begin{tabular}{lll}
\hline Variables & Goal & Objective \\
\hline $\begin{array}{l}\text { Position of the item selected with } \\
\text { the pointer during the game }(\mathrm{X},\end{array}$ & Define areas of interest and interaction with the system. \\
Y) & Determine the number of clicks made at each level & O1; O3 \\
\hline Attempts & Determine the number of errors & O1 \\
\hline Errors & $\begin{array}{l}\text { Determining the number of seconds that elapsed between when the game is } \\
\text { stopped and interaction with the session leader }\end{array}$ \\
\hline Response time & $\begin{array}{l}\text { The session leader determines whether the user looked at them when the } \\
\text { game was stopped }\end{array}$ \\
\hline Interaction with visual contact O2 & $\begin{array}{l}\text { The session leader determines whether the user interacted without visual O1; O2 } \\
\text { contact when the game was stopped }\end{array}$ \\
\hline Interaction without visual contact & Determines participants areas of interest \\
\hline $\begin{array}{l}\text { Gaze and pupil information } \\
\text { during the game }\end{array}$ &
\end{tabular}




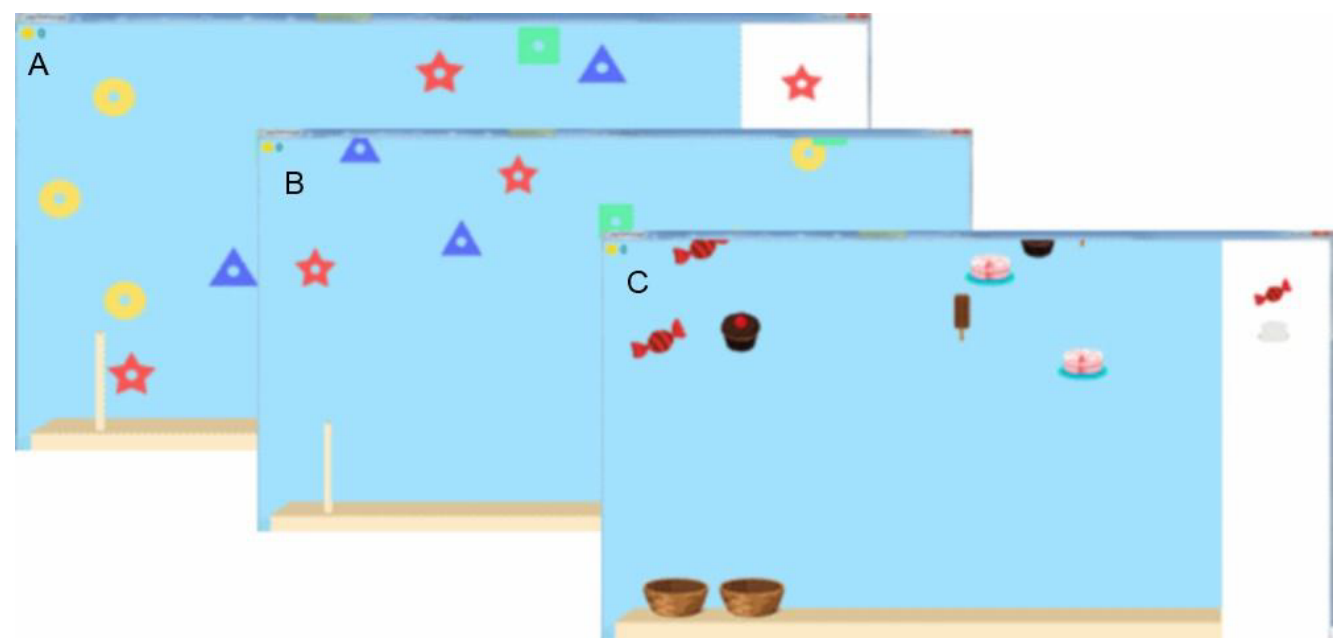

Fig. 1. Game levels. A illustrates the interface of the first level, B shows the appearance of the second level, and C shows the third level.

Table 2

Features of levels of difficulty

\begin{tabular}{llllll}
\hline Level & Visual Element & Support & Area & Stops owing to error & Stops every 30 sec. \\
\hline Level 1 & Red stars & Yes & Interaction & No & Yes \\
Level 2 & Yellow circles & No & Interaction, Memory & Yes & Yes \\
Level 3 & Sweets or cakes & Yes & Interaction, Memory & Yes & Yes \\
& & & Attention & & \\
\hline
\end{tabular}

The system contains a set of games divided into 3 levels of difficulty-level 1, level 2 and level 3and involved collecting elements which appeared on the screen (see Figure 1).

The difficulty of the levels were defined by the degree of interaction required and the area that were worked on in each of them (see Table 2)

The game has been designed to be configurable to suit the needs of each user. Therefore many options can be set, from the objects that appear on the screen to the duration of the game. But due to the fact that one of the objectives of the study is to establish indicators, the same settings for all users have been required.

The duration of the test was about 12 minutes divided into 1 minute to explain the purpose of the game before starting each level, and 3 minutes for each exercise. During this time, the greatest number of elements had to be selected. At each level, users had to collect a different type of item. At the first level, participants had to collect red stars, at the second level, yellow circles and the last level, sweets or cakes, depending on the game instructions. To find out which element should be collected at this level, it was displayed on the right side of the screen.

In addition to the purpose of the game itself, the aim is to work on and assess the interaction with the session leaders and the time taken for them to provide interaction. The game is designed to stop every

30 seconds automatically or with the user's errors at the second and third level to assess communication skills and force interaction with the session leader. When this happens, all the items on the screen disappear. This break in the game forces the child with ASD to ask for help in order to 
resume the game, i.e. the child has to interact with the session leader if they wish to continue playing. The system records two types of interaction:

(1) The child communicates with the session leader and looks into their eyes (interaction with eye contact)

(2) The child communicates with the session leader without looking into their eyes, by using a gesture, words, etc. (interaction without eye contact).

To save the two types of interaction mentioned above, the session leader marks on the keyboard that there was interaction with the child with ASD. Thus, pressing the "space" bar indicates that interaction with eye contact has taken place, and pressing the ' 0 ' key indicates that the interaction without eye contact has occurred.

\subsection{Selecting the environment}

Once the levels and variables to be analyzed have been defined, it is then necessary to define and select the best environment in which to play the games. The games were conducted during each child's session, with the presence of the educationalist leading the session and the participant. Since the objective was to develop interaction skills, either a professional or family member had to participate in the game. Owing to the fact that people with ASD find it difficult to react to changes, it is necessary at the start of each session with the professional to have previously informed the child that they are going to spend 10 minutes on the session in order to do tests on the computer, and also to introduce the person who is going to be the observer throughout the tests. The tests were conducted in a classroom that the participating children already knew. The classroom was equipped with desks and chairs adapted to the children, which contributed to a more comfortable environment while the tests were being carried out. Moreover, a classroom without windows was selected so as to maintain artificial lighting with as few variables as possible between tests, so as not to affect data being captured by the eyetracker. During the game, the participant sits opposite the tactile screen and indicates to the educationalist to their right, using the tactile pointer, which element, they wish to select. Meanwhile, the observer sits behind both, without interfering in the data being captured by the eyetracker.

\subsection{Configuration and analysis of the eyetracker}

The participants sit in front of a computer with the eyetracker system installed. During the tests, the eyetracker was positioned on the lower part of the touch screen and fastened using the devices own support to obtain the most reliable possible data. The child sat on a chair aligned with the center of the screen at a distance of 56 centimeters from the latter. Once the child was properly seated, a check was made to ensure that the user's eyes were aligned with the center of the screen. To calibrate the eyetracker and make sure that it was capturing reliable data, the devices own software was used whereby the user had to focus their gaze on 9 points for a period of some seconds. Likewise and as stated in the Materials section, a $40 \mathrm{~cm}$ tactile pointer was used so as to interfere as little as possible with capturing of the gaze and pupil using the eyetracker. To obtain data using the eyetracker, an attempt was made to cover different factors that might affect variation in the pupils [49], such as maintaining the same intensity of light in the classroom using artificial light, the same $270 \mathrm{~cd} / \mathrm{m}^{2}$ screen brightness during all the tests, and the removal of visual stimuli that might distract the participant. For the eyetracker to be able to carry out data analysis, the data captured was cleaned by disregarding blinking and also any also zero positions owing to loss of data that there may have been 
when interacting with the educationalists.

\section{Results}

This section shows the objective results obtained after comparing the two groups: the clinical group and the control group. This study analyses the cognitive skills, in particular, where the participants with ASD, and the participants in the control group had a tendency to interact with the system and the session leader. To this end, this section is divided into three parts: First, the results obtained by the interaction between users and session leader (O2). Second, the game outcome showing those parameters generated via the game $(\mathrm{O} 1, \mathrm{O} 3)$, and lastly, the eyetracker results $(\mathrm{O} 3)$. This last section describes the results obtained with the sensor.

\subsection{Interaction with leader session results}

The Mann-Whithney test showed that response time for the clinical group $(M=21.008, S D=25.24)$ and control group evidenced significant differences, due to the fact that the reaction time of the first group was greater than the second group $(\mathrm{M}=4.52 \mathrm{sec}, \mathrm{SD}=3.40),(\mathrm{z}=-7.55, \mathrm{p}<0.05)$ (see Figure 2 ); either there were stops caused by user error (Clinical group : $\mathrm{M}=11.50, \mathrm{SD}=24.81$; Control group: $\mathrm{M}=1.88, \mathrm{SD}=1.70),(\mathrm{z}=-3.47, \mathrm{p}<0.05)$ or the stops occured every 30 seconds automatically to force the interaction. (Clinical group: $\mathrm{M}=17.66, \mathrm{SD}=21.08$; Control group: $\mathrm{M}=4.39, \mathrm{SD}=3.16$ ), $(\mathrm{z}=-5.801, \mathrm{p}<0.05)$ (see Figure 3).

Besides, the test indicated that there were differences in relation to the type of user interaction, i.e. the clinical group $(\mathrm{M}=36, \mathrm{SD}=38.18)$ looked less into the session leader's eyes than the control group $(\mathrm{M}=101, \mathrm{SD}=60),(\mathrm{z}=-6.627, \mathrm{p}<0.05)$. Moreover, the clinical groups $(\mathrm{M}=14.13, \mathrm{SD}=$ 18.24) needed more time to interact when looking into the eyes than the control group $(M=3.67$, Average response time

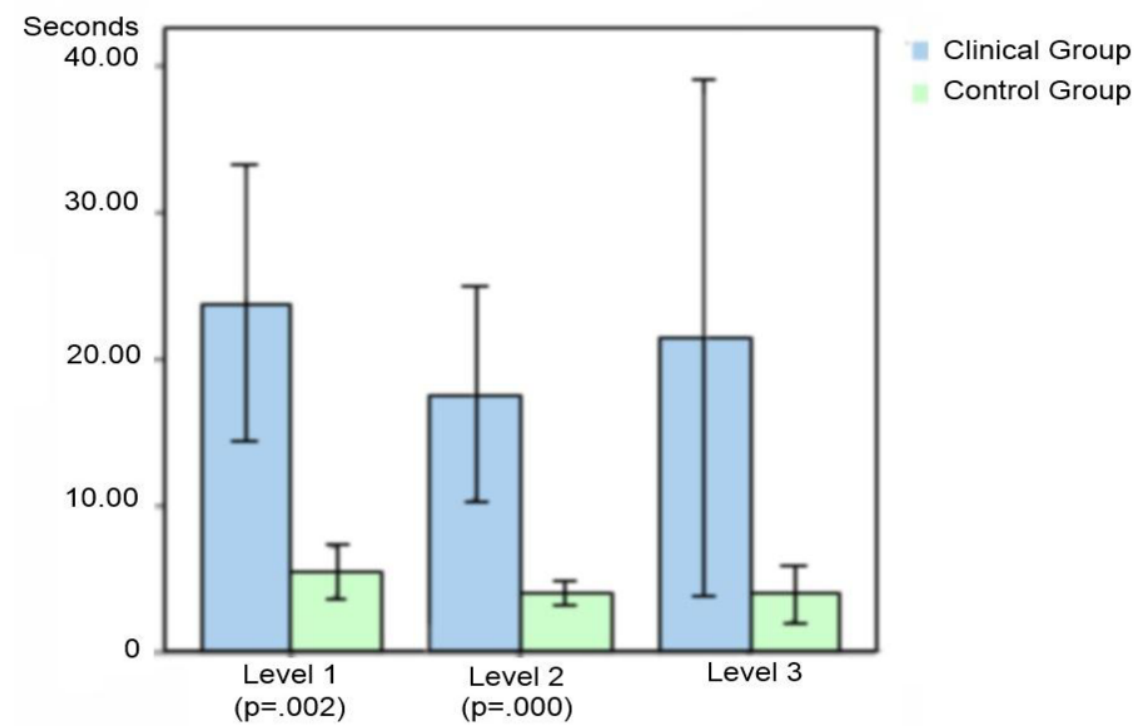

Fig. 2. Average response time. This figure shows the average response time used by users after an event occurred in the sytem. 

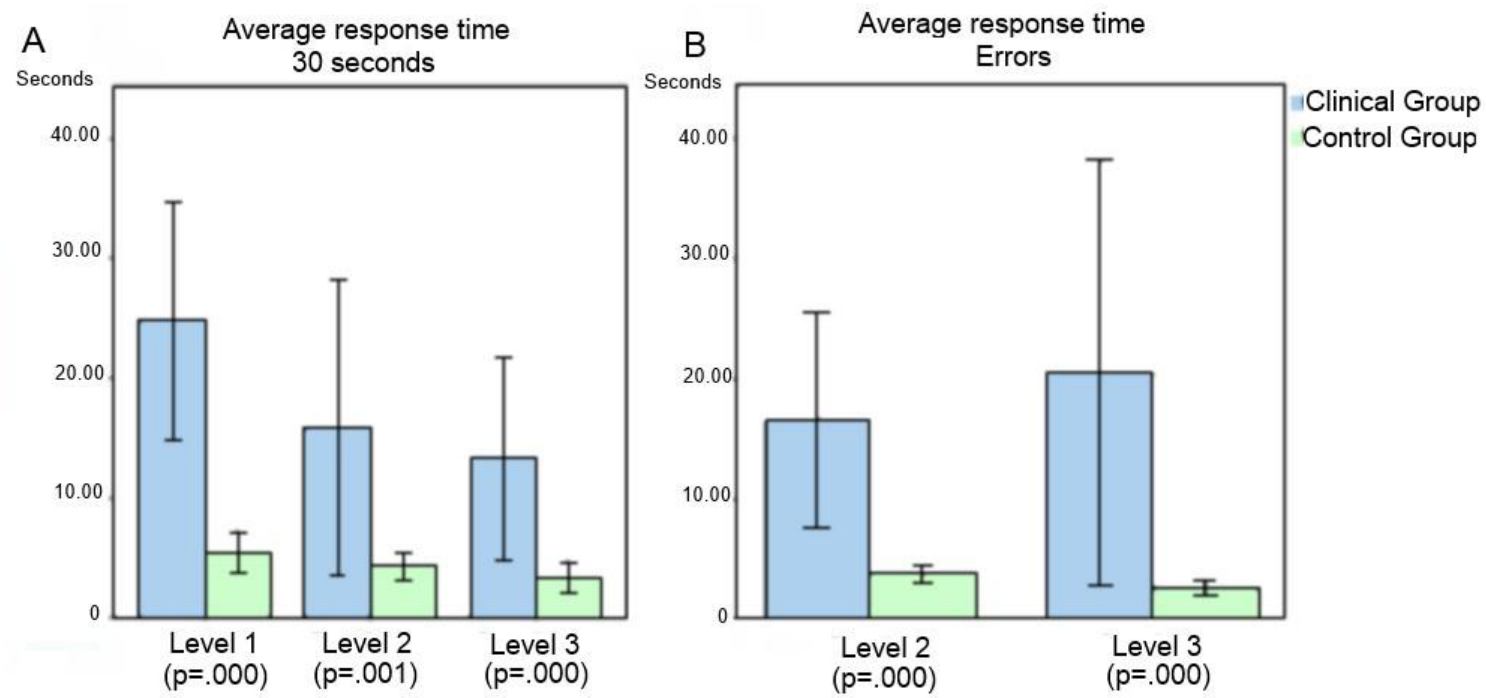

Fig. 3. Type of average response time. A shows the average response time when the users provided an interaction looking into eyes. B shows the average response time when the users did not provide an interaction looking into eyes.
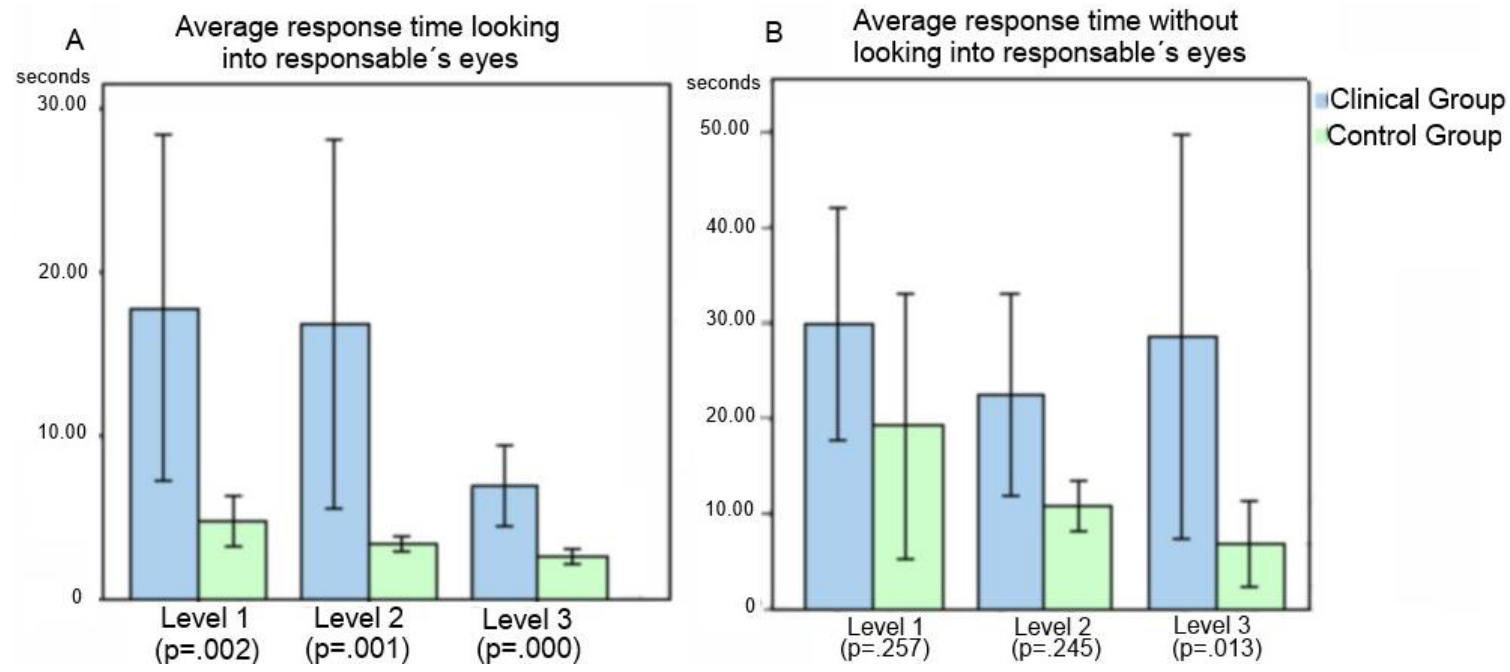

Fig. 4. Type of average response time. A shows the average response time of participants after the automatic stops every 30 seconds. B shows the average response time of participants after a stop caused by an error (at the first level, stops caused by errors were not recorded).

$\mathrm{SD}=2.16),(\mathrm{z}=-6.305, \mathrm{p}<0.05)$. As can be observed in Figure 4, the response time decreased as the users moved forward in the game when the clinical group provided interaction with eye contact. However, for the control group, the reaction time decreased regardless of the type of interaction.

Nevertheless, the descriptive analysis showed the clinical group interacted for a longer period looking into the session leaders eyes than via gestures or words $(\mathrm{M}=22.54, \mathrm{SD}=23.31)$. Additionally, the correlation between the response time and the number of times of interaction with eye contact was analyzed. Thus, the trend of both groups in this aspect was able to be checked. As a result, regarding the clinical group, a moderate correlation $\mathrm{r}=-0.481$, which was both negative and significant, was 
Table 3

Percentage of people who did not overcome the levels

\begin{tabular}{lllll}
\hline Group & Level & Avg. number of interactions & Threshold & \% overcoming \\
\hline Clinical Group & Level 1 & 47.86 & 10 & $90 \%$ \\
& Level 2 & 35.08 & 7 & $86 \%$ \\
& Level 3 & 29.08 & 6 & $85 \%$ \\
Control Group & Level 1 & 123.47 & 25 & $100 \%$ \\
& Level 2 & 86.35 & 17 & $100 \%$ \\
& Level 3 & 78.82 & 16 & $95 \%$ \\
\hline
\end{tabular}

Table 4

Rights and wrongs

\begin{tabular}{llll}
\hline Group & Events & Mean & Standard Deviation \\
\hline Clinical Group & Rights & 24.66 & 22.35 \\
& Wrongs & 7.03 & 7.34 \\
Control Group & Rights & 79.41 & 31.48 \\
& Wrongs & 14.15 & 13.43 \\
\hline
\end{tabular}

obtained $(\mathrm{p}<0.05)$. Regarding the control group, a moderate correlation $\mathrm{r}=-0.403$, both negative and significant, was also obtained $(\mathrm{p}<0.05)$.

\subsection{Interaction with the game results}

Three aspects were analyzed in order to assess the interaction with the game: 1) the percentage of people who did not overcome any levels, 2) the rights and wrongs during the game and 3) pointer position. To determine the percentage of people who completed the levels, it was established that the user had to exceed a $20 \%$ threshold in terms of the average number of interactions provided by their group at each level (see Table 3). Moreover, $66 \%$ of people in the clinical group who did not exceed level 3 provided two or fewer interactions during the level.

As Table 4 shows, the Mann-Whithney test indicated that the only significant difference was between the rights and wrongs of the clinical group and control group (errors: $Z=-4.37, p=.000$; rights: $Z=-7.902)$. Differences between pointer positions $(p=.147)$ were not deemed to be significant.

\subsection{Eye Tracker results}

The results obtained from the eyetracker are shown in this section. To carry out an analysis of the data captured by the eyetracker, an initial data cleaning phase was conducted in the course of which any zero positions recorded and produced by the last pointer used were disregarded. There were no significant differences between the average gaze positions when the users were playing $\mathrm{z}(\mathrm{Px}, \mathrm{Py})=(-$ $0.255,-0.300), \mathrm{p}>0.05)$, although there were differences between the pupil diameter, as it can be seen in Figure 5, these being greater the size of the control group ( $z=-3.84 ; p<0.05)$ (see Tables 5 and 6).

Nevertheless, as can be observed in Table 6, differences were found between two groups when analyzing the eye movement when there were stops $(\mathrm{z}(\mathrm{Px}, \mathrm{Py})=(-2.439,-5.029), \mathrm{p}<0.05))$. This data indicates the participants state when the game was stopped and that there were no distracting elements on the screen. The control group kept their eyes focused on the upper right of the screen, although the clinical group performed an average exploration on the bottom right of the screen. 
Table 5

Gaze position: Gaming

\begin{tabular}{llll}
\hline Group & Position & Mean & $\begin{array}{l}\text { Standard } \\
\text { Deviation }\end{array}$ \\
\hline Clinical Group & Gaze X position & -5.48 & 67.89 \\
& Gaze Y position & 57.49 & 63.98 \\
& Pupil Diameter & 3.61 & 0.70 \\
Control Group & Gaze X position & -3.45 & 40.73 \\
& Gaze Y position & 158 & 46.44 \\
& Pupil Diameter & 3.81 & 1.02 \\
\hline
\end{tabular}

Table 6

Gaze position: Game stop

\begin{tabular}{llll}
\hline Group & Position & Mean & $\begin{array}{l}\text { Standard } \\
\text { Deviation }\end{array}$ \\
\hline Clinical Group & Gaze X position & 6.86 & 14.33 \\
& Gaze Y position & 22.52 & 627.55 \\
& Pupil Diameter & 3.29 & 1.10 \\
Control Group & Gaze X position & 21.15 & 41.88 \\
& Gaze Y position & 64.29 & 45.58 \\
& Pupil Diameter & 3.79 & 0.77 \\
\hline
\end{tabular}

\section{Discussion and conclusions}

Both professionals and family members of children with ASD work and seek alternatives so that people with ASD may improve on their weaknesses day by day, thus ensuring that they can lead an independent life $[10,19]$. The purpose of this pilot study was to assess how a system designed for people with ASD can help them achieve this objective, incorporating this system as a tool into their cognitive rehabilitation.

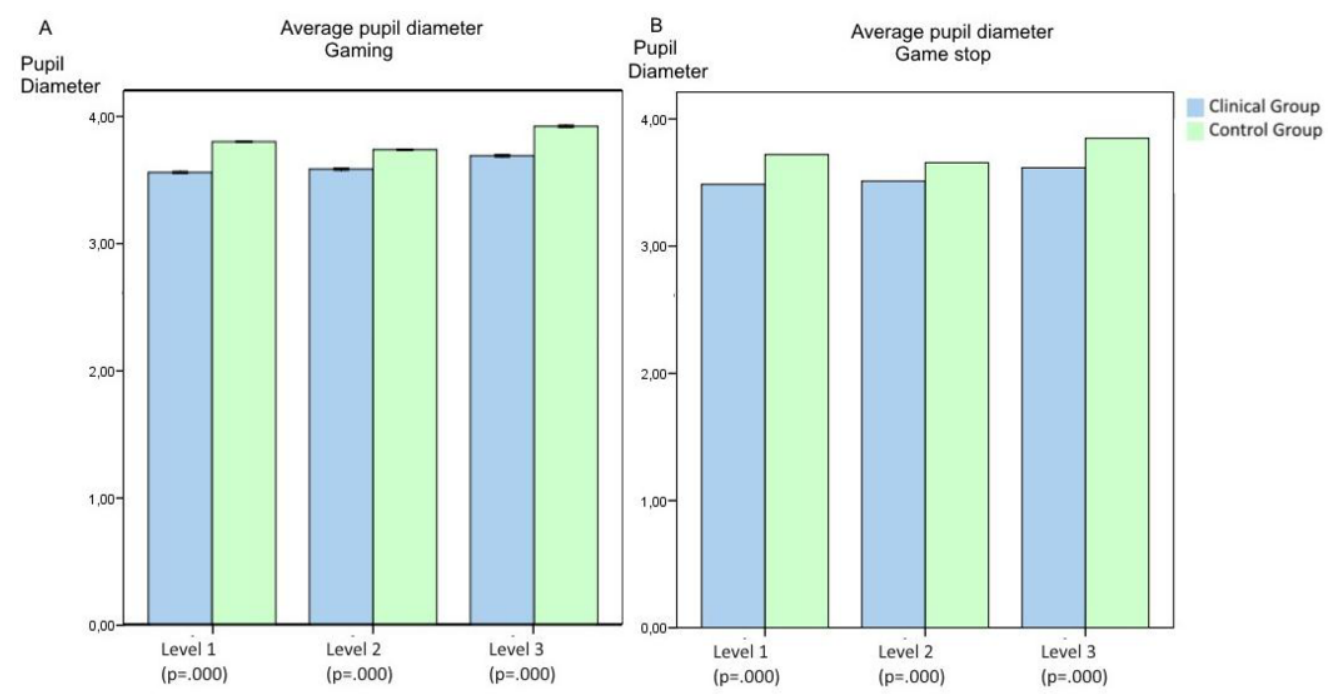

Fig. 5. Pupil diameter size. A shows the average pupil diameter when the game is running. B shows the average pupil size 
when the game is stopped.

The literature contains studies where several technologies are used to help people with ASD obtaining positive results $[49,50]$. Nevertheless, these studies present as limitations they are not collaborative. This means, the user only works with the application, missing the interaction with someone else. This interaction allows to work social skills [19].

The results obtained from this preliminary study confirm the second objective, in which a desire was expressed to assess interaction with people during play. It was observed that there had been an improvement by reducing the reaction time throughout levels (see Figure 4) when the interaction involved looking into the eyes, this being an indicator that the system could help in cognitive rehabilitation. Furthermore, both groups evidenced the same behavior when they interacted with the session leader through eye contact, that is to say, as users provided a greater number of interactions looking into the eyes the less time it took them to interact with the session leader. This could be because the participants understood that the quicker they ask for help or interact with the session leader looking into their eyes, the faster they can play again.

As for objective 3 , this might be determined as an objective variable to analyze the reaction time of participants with ASD. There was a high average reaction time - 21.08 seconds after an interruption occurred in the system. Rights and wrongs may be considered as a further indicator because, as Table 4 shows, there are significant differences in relation to the rights and wrongs recorded in the system. The high number of errors (wrongs) made by the control group are thought to be because users provided more interactions with the game and session leaders than the clinical group.

Another major indicator is the visual contact, as eye contact predominates when children ask for help and when interacting with the session leader. Interaction time might also be deemed to be a further indicator to be taken into account. Looking at Figure 3B, it was ascertained that interaction time increased when the clinical group interacted with the session leader via gestures or words at Level 3. This could be the case since users who were more affected spent more time answering, which might be because they could not finish the level or because they provided no interaction (see Table 3 ).

As regards screen exploration, there were no significant differences between the clinical and control group when the game was running (see Table 5). Nevertheless, there were differences when the game was stopped (see Table 6), since the clinical group fixed their gaze on the bottom of the screen, as shown in several research cases. This indicator can help professionals ascertain how to display new elements or concepts to them $[51,52]$.

These results are in line with other studies, which have analyzed how children with autism scan static pictures from the bottom to up, as the authors indicate J. Warnet, et al. [53], particular faces. The mayor concentration of children with ASD' gaze is located in the mouth region and the control group in the eyes region. After analyzing the results obtained in this study, a longitudinal study will then be carried out. This first study phase has helped to obtain preliminary results for the indicators assessed both for the control group and the clinical group. A longitudinal study will be able to help ascertain how these parameters evolve and whether the clinical group approaches the results obtained by the control group. This might entail an improvement in the areas worked on and also help to ascertain the effectiveness of the system itself as a rehabilitation tool. In short, this system could help in cognitive rehabilitation and the working interaction area affected by ASD. Therefore, the authors conclude that new technologies make it possible not only to create environments adapted to each people needs, but also to use them as a cognitive rehabilitation tool.

\section{Acknowledgments}


The authors would like to thank all participants involved in the study. The authors would also like to thank the company Datinet, and the Association of Parents of People with Autism and other Autism Spectrum Disorders (APNABI) and school "Colegio Vizcaya".

\section{References}

[1] B.M. Kuehn, Data on autism prevalence, trajectories illuminate socioeconomic disparities, Journal of the American Medical Association 307 (2012), 2137-2138.

[2] J. Baio, Prevalence of autism spectrum disorders: Autism and developmental disabilities monitoring network, 14 sites, United States, 2008, Morbidity and mortality weekly report, Surveillance summaries, Centers for Disease Control and Prevention 61 (2012), 1-24.

[3] L.Y. Tsai, Sensitivity and specificity: Dsm-iv versus dsm-5 criteria for autism spectrum disorder, American Journal of Psychiatry 169 (2012), 1009-1011.

[4] G. Esposito and P. Venuti, Symmetry in infancy: analysis of motor development in autism spectrum disorders, Symmetry 1 (2009), 215-225.

[5] H.-J. Kim, H.-S. Kim, M.-H. Choi, I.-H. Lee, S.-P. Hong, N.-R. You, S.-C. Chung, D.-W. Lim and J.-H. Yi, Response time of visual matching task and heart rate in children with attention deficit hyperactivity disorder (adhd), Bio-Medical Materials and Engineering 24 (2014), 987-991.

[6] Rodríguez-Barrionuevo and M. Rodríguez-Vives, Clinical diagnosis of autism, Journal of Neurology 34 (2002), $72-77$.

[7] Data, Centers for disease control and prevention march 2014, Available at: http://www.cdc.gov/ncbddd/autism/data.html, last accessed: March 13 $3^{\text {th }}, 2015$.

[8] S. López Gómez, R.M. Rivas Torres and E.M. Taboada Ares, Reviews on autism, Latin American Journal of Psychology 41 (2009), 555-570.

[9] M. Elsabbagh, G. Divan, Y.-J. Koh, Y.S. Kim, S. Kauchali, C. Marcín, C. Montiel-Nava, V. Patel, C.S. Paula, C. Wang, et al., Global prevalence of autism and other pervasive developmental disorders, Autism Research 5 (2012), 160-179.

[10] E. Bekele, J. Crittendon, Z. Zheng, A. Swanson, A. Weitlauf, Z. Warren and N. Sarkar, Assessing the utility of a virtual environment for enhancing facial affect recognition in adolescents with autism, Journal of Autism and Developmental Disorders 44 (2014), 1-10.

[11] S. Parsons, A. Leonard and P. Mitchell, Virtual environments for social skills training: Comments from two adolescents with autistic spectrum disorder, Computers \& Education 47 (2006), 186-206.

[12] J.A. Ehrlich and J.R. Miller, A virtual environment for teaching social skills: Avisss, Computer Graphics and Applications 29 (2009), 10-16.

[13]P. Mitchell, S. Parsons and A. Leonard, Using virtual environments for teaching social understanding to 6 adolescents with autistic spectrum disorders, Journal of Autism and Developmental Disorders 37 (2007), 589-600.

[14] Y. Kamio, N. Inada, T. Koyama, E. Inokuchi, K. Tsuchiya and M. Kuroda, Effectiveness of using the modified checklist for autism in toddlers in two-stage screening of autism spectrum disorder at the 18-month health check-up in japan, Journal of Autism and Developmental Disorders 44 (2014), 194-203.

[15] M. Bellani, L. Fornasari, L. Chittaro and P. Brambilla, Virtual reality in autism: state of the art, Epidemiology and Psychiatric Sciences 20 (2011), 235-238.

[16] S. Parsons and P. Mitchell, The potential of virtual reality in social skills training for people with autistic spectrum disorders, Journal of Intellectual Disability Research 46 (2002), 430-443.

[17] G. Herrera, R. Jordan and L. Vera, Abstract concept and imagination teaching through virtual reality in people with autism spectrum disorders, Technology and Disability 18 (2006), 173-180.

[18] M.R. Kandalaft, N. Didehbani, D.C. Krawczyk, T.T. Allen and S.B. Chapman, Virtual reality social cognition training for young adults with high-functioning autism, Journal of Autism and Developmental Disorders 43 (2013), 34-44.

[19] B. Robins, K. Dautenhahn, E. Ferrari, G. Kronreif, B. Prazak-Aram, P. Marti, I. Iacono, G.J. Gelderblom, T. Bernd, F. Caprino, et al., Scenarios of robot-assisted play for children with cognitive and physical disabilities, Interaction Studies 13 (2012), 189-234.

[20] I. Yamamoto, N. Inagawa, M. Matsui, K. Hachisuka, F. Wada and A. Hachisuka, Research and development of compact wrist rehabilitation robot system, Bio-Medical Materials and Engineering 24 (2014), 123-128.

[21]E.T. Bekele, U. Lahiri, A.R. Swanson, J.A. Crittendon, Z.E. Warren and N. Sarkar, A step towards developing adaptive robot-mediated intervention architecture (aria) for children with autism, IEEE Transactions on Neural Systems and Rehabilitation Engineering 21 (2013), 289-299. 
[22] I. Werry, K. Dautenhahn and W. Harwin, Investigating a robot as a therapy partner for children with autism, Procs AAATE 20016 (2001).

[23] B. Robins, K. Dautenhahn, R. Te Boekhorst and A. Billard, Robotic assistants in therapy and education of children with autism: can a small humanoid robot help encourage social interaction skills? Universal Access in the Information Society 4 (2005), 105-120.

[24] B. Huskens, R. Verschuur, J. Gillesen, R. Didden and E. Barakova, Promoting question-asking in school-aged children with autism spectrum disorders: Effectiveness of a robot intervention compared to a human-trainer intervention, Developmental Neurorehabilitation 16 (2013), 345-356.

[25] B. Robins, K. Dautenhahn and P. Dickerson, From isolation to communication: a case study evaluation of robot assisted play for children with autism with a minimally expressive humanoid robot, Second International Conferences on Advances in Computer-Human Interactions, Cancun, 2009, pp. 205-211.

[26] B. Vanderborght, R. Simut, J. Saldien, C. Pop, A.S. Rusu, S. Pintea, D. Lefeber and D.O. David, Using the social robot probo as a social story telling agent for children with asd, Interaction Studies 13 (2012), 348-372.

[27] J. Lee, H. Takehashi, C. Nagai, G. Obinata and D. Stefanov, Which robot features can stimulate better responses from children with autism in robot-assisted therapy? International Journal of Advanced Robotic Systems 9 (2012).

[28] C. Murdock, J. Ganz and J. Crittendon, Use of an ipad play story to increase play dialogue of preschoolers with autism spectrum disorders, Journal of Autism and Developmental Disorders 43 (2013), 2174-2189.

[29] G. Herrera, X. Casas, J. Sevilla, L.R. Escribano, C. Pardo, C.P. Carpio, J. Plaza, R. Jordan and S. Le Groux, Pictogram room: Application of natural interaction technologies for the development of children with autis, Annuary of Clinical and Health Psychology 8 (2012), 41-46.

[30]L. Fornasari, L. Chittaro, L. Ieronutti, L. Cottini, S. Dassi, S. Cremaschi, M. Molteni, F. Fabbro and P. Brambilla, Navigation and exploration of an urban virtual environment by children with autism spectrum disorder compared to children with typical development, Research in Autism Spectrum Disorders 7 (2013), 956-965.

[31]A. Blanc, Brigadoon: An innovative online community for people dealing with Asperger's syndrome and autism, Available at: http://braintalk. blogs. com/brigadoon/, last accessed: 2010.

[32] D.C. Strickland, C.D. Coles and L.B. Southern, Jobtips: A transition to employment program for individuals with autism spectrum disorders, Journal of Autism and Developmental Disorders 43 (2013), 2472-2483.

[33]E. Delano, Improving written language performance of adolescents with asperger syndrome, Journal of Applied Behavior Analysis 40 (2007), 345-351.

[34] N. Aresti-Bartolome and B. Garcia-Zapirain, Technologies as support tools for persons with autistic spectrum disorder: A systematic review, International Journal of Environmental Research and Public Health 11 (2014), 7767-7802.

[35] C.E. Hughes, C.B. Stapleton, D.E. Hughes and E.M. Smith, Mixed reality in education, entertainment, and training, Computer Graphics and Applications 25 (2005), 24-30.

[36] D. Moore, Y. Cheng, P. McGrath and N. J. Powell, Collaborative virtual environment technology for people with autism, Focus on Autism and Other Developmental Disabilities 20 (2005), 231-243.

[37] U. Lahiri, E. Bekele, E. Dohrmann, Z. Warren and N. Sarkar, Design of a virtual reality based adaptive response technology for children with autism, IEEE Transactions on Neural Systems and Rehabilitation Engineering 21 (2013), $55-64$.

[38] B.O. Ploog, A. Scharf, D. Nelson and P.J. Brooks, Use of computer-assisted technologies (cat) to enhance social, communicative, and language development in children with autism spectrum disorders, Journal of Autism and Developmental Disorders 43 (2013), 301-322.

[39] E.S. Kim, L.D. Berkovits, E.P. Bernier, D. Leyzberg, F. Shic, R. Paul and B. Scassellati, Social robots as embedded reinforcers of social behavior in children with autism, Journal of Autism and Developmental Disorders 43 (2013), 10381049.

[40] K.C. Welch, U. Lahiri, C. Liu, R. Weller, N. Sarkar and Z. Warren, An affect-sensitive social interaction paradigm utilizing virtual reality environments for autism intervention, in: Human-Computer Interaction, Ambient, Ubiquitous and Intelligent Interaction, Springer, Berlin Heidelberg, 2009, pp. 703-712.

[41] G. Dillon and J. Underwood, Computer mediated imaginative storytelling in children with autism, International Journal of Human-Computer Studies 70 (2012), 169-178.

[42] W.D. Reid, Virtual reality in pediatric neurorehabilitation: Attention deficit hyperactivity disorder, autism and cerebral palsy, Neuroepidemiology 36 (2011), 2-18.

[43] B. Scassellati, H. Admoni and M. Mataric, Robots for use in autism research, Annual Review of Biomedical Engineering 14 (2012), 275-294.

[44]F.T. Nicolás, Assistive technologies for people with autism spectrum disorders: A guide for teachers, CPR Murcia I (2004). 
[45] O. Grynszpan, J.-C. Martin and J. Nadel, Multimedia interfaces for users with high functioning autism: An empirical investigation, International Journal of Human-Computer Studies 66 (2008), 628-639.

[46] L. Torii, K. Ohtani and N. Ishii, Development and study of support applications for autistic children, Software Engineering, Artificial Intelligence, Networking and Parallel/Distributed Computing (SNPD), Honolulu, 2013, pp. 420425.

[47] B. Ingersoll and A. Wainer, Initial efficacy of project impact: A parent-mediated social communication intervention for young children with asd, Journal of Autism and Developmental Disorders 43 (2013), 2943-2952.

[48] S. Powell, The use of computers in teaching people with autism, in: Autism on the agenda: papers from a National, Autistic Society Conference, London, 1996.

[49] S.M. Srinivasan, K.A. Lynch, D.J. Bubela, T.D. Gifford and A.N. Bhat, Effect of interactions between a child and a robot on the imitation and praxis performance of typically developing children and a child with autism: A preliminary study, Perceptual \& Motor Skills 116 (2013), 885-904.

[50] F. Ke and T. Im, Virtual-reality-based social interaction training for children with high-functioning autism, The Journal of Educational Research 106 (2013), 441-461.

[51] M.T. Mercadante, E.C. Macedo, P.M. Baptista, C.S. Paula and J.S. Schwartzman, Saccadic movements using eyetracking technology in individuals with autism spectrum disorders: Pilot study, Archives of Neuropsychiatry 64 (2006), 559-562.

[52] M.R. Swanson, G.C. Serlin and M. Siller, Broad autism phenotype in typically developing children predicts performance on an eyetracking measure of joint attention, Journal of Autism and Developmental Disorders 43 (2013), 707-718.

[53] J.B. Wagner, S.B. Hirsch, V.K. Vogel-Farley, E. Redcay and C.A. Nelson, Eye-tracking, autonomic, and electrophysiological correlates of emotional face processing in adolescents with autism spectrum disorder, Journal of Autism and Developmental Disorders 43 (2013), 188-199. 